\title{
Systematic Review of Social Networking Support Groups for Genetic- Disorders Pain Management
}

\author{
Sadaf Ashtari \\ California State University, \\ Sacramento \\ sadaf.ashtari@csus.edu
}

\author{
Joseph Taylor \\ California State University, \\ Sacramento \\ joseph.taylor@csus.edu
}

\author{
Glen Lai \\ California State University, \\ Sacramento \\ glenlai@csus.edu
}

\begin{abstract}
The pervasive opioid crisis in the United States highlights the challenges that many individuals have with pain management. One population that struggles with pain management are communities that experience genetic disorders. In this paper we present a literature review that examines the findings of the extant literature regarding pain management for genetic disorders on social media. We find that while research regarding social media in healthcare management has been increasing, there are still relatively few papers that address social media and pain management, We present a research agenda for the study of pain management techniques enabled by social media.
\end{abstract}

\section{Introduction}

The goal of this study is to determine the degree to which social networking/online community applications are being used by consumers and patients to share and find techniques for pain management of genetic disorders. Through this systematic review we present a framework to better understand the efficacy of social networking applications in assisting patients with their management of genetic-disorder related pain. The two research questions that will be addressed in this study are:

1- What is the evidence base of research that addresses the efficacy of social networking tools for use in pain mitigation among people with genetic disorders?

2- Which social networking tools are patients with genetic-disorder conditions which include chronic pain using more frequently and what aspects of social media tools are deemed most useful (e.g., the ability to share/find/connect)?

Technology provides individuals with a large variety of ways in which to develop communities. The advent of information technology enables dispersed communities that allow like-minded individuals to share information and collaborate together [1]. The power of social media to build community is especially impactful in small distributed groups. Social networks can enable groups to collectively address challenges [2]. As the collaborative affordances of social media diffuse across various communities of chronic disease patients, scholars and practitioners must assess our current knowledge regarding how social media and other emerging collaborative technologies are currently understood in the literature.

Chronic diseases represent a wide range of conditions that require long term management [3]. One important category of chronic diseases is related to genetic disorders. Genetic disorders can span generations and present a unique opportunity around which for communities to develop. The spectrum of rare and genetic disorders and their symptoms is broad, and every human system has its own unique instance of a given disorder. Since there are often no absolute cures for genetic disorders, treatments are primarily focused on maintaining quality of life or slowing its degradation [4]. While many patients try physical therapy or pain-relieving medications, they often also discover throughout the course of their daily lives various highly effective non-medical solutions for decreasing pain. These unique methods of reducing pain are often shared and discovered across various websites and social media platforms. By reviewing different studies in the fields of pain management and social networking, the efficacy of sharing pain-related therapies through different social networking services among genetic-disordered patients is investigated and opportunities to increase the efficacy of those systems is documented.

\section{Research Context}

Genetic disorders encompass an enormous group of disorders most of which do not have a cure and as a result, support is key in their treatment. A genetic 
disorder is a disease that is caused by a change in the DNA sequence away from the normal sequence. Genetic disorders are categorized based on the mutation in one gene (monogenic disorder), mutation in multiple genes (multifactorial inheritance disorder), and combination of gene mutations and environmental factors, or by damage to chromosomes (changes in the number or structure of entire chromosomes). Disorders that are caused by mutation of one gene are inherited from the parents and an individual will have this disorder from birth such as Sickle Cell Disease [5]. Over 4000 human diseases are caused by single-gene defects. Other diseases are caused by mutation of multiple genes during a person's life and their combination with environmental factors (such as smoking). These mutations are not inherited from a parent and can include many cancers, heart disease, and diabetes [6].

The spectrum of rare and genetic diseases and their symptoms are wide and every organ system has its own categories of diseases. Apart from the medical challenges of genetic disorders, the lack of financial and market incentives to treat or cure genetic disorders is another obstacle to achieve rare and genetic diseases treatment.

Based on the Global Gene Organization fact sheet in 2017, $10 \%$ of the US population, equal to approximately 30 million people, are living with rare diseases. Approximately 7000 different types of rare diseases have been discovered so far. Around $80 \%$ of all rare disease patients are diagnosed with 350 rare diseases. Also, $80 \%$ of rare diseases are genetic disorders and are present throughout a person's life. The US Congress in the Orphan Drug Act of 1983 defined rare disease as a condition that affects fewer than 200,000 people. The Orphan Drug Act (ODA) was encouraging medical companies to develop new drugs for rare diseases by offering financial incentives to them. However, during the first 25 years of the ODA, only 326 new drugs were approved by the FDA and brought to market for all rare diseases.

High medical expenditures are another challenge for genetic disorders patients and healthcare providers. For example, the medical cost of neuromuscular disorders in the U.S. in 2017 was around $\$ 20 \mathrm{~K}$ per year and lost income was almost $\$ 15 \mathrm{~K}$. Furthermore, the total hospital costs for Cystic Fibrosis patients in the U.S. was estimated $\$ 1.1$ billion per year [7]

The life span of people that are diagnosed with genetic disorders could be the same as healthy people, but their quality of their life may be different. Since there are no known cures for genetic disorders, patients mostly try to maintain or slow down the degradation of their quality of life. They may try physical therapy or pain killing medication. Overall, the objective of most treatments is to reduce the symptoms of the disorders to improve patient's quality of life [5].

Scholars have identified many ways in which social media influences health related activities. The interactive nature of content creation supports the introduction of more voices into healthcare related knowledge development. Active social media management has been found to drive more user generated content [8]. With greater levels of content users have more opportunities to learn about health related conditions. Social media has been associated with health promotion and behavior change [9]. Social media has also been found to be of benefit in assisting patients in learning from others regarding selfmanagement [10]. The impacts of social media in knowledge creation extend beyond just patients. Social media has been demonstrated as a means by which professional development may be enabled within the healthcare industry [11]. As healthcare professionals are provided with expanding outlets for interaction with others through social media, this technology has been identified as a means of medical knowledge creation [12]. While the general benefits of social media in promoting community development for healthcare have been addressed in the extant literature, the community for those suffering from rare diseases represents a unique subset of the broader healthcare industry. The difficulty of managing rare genetic diseases presents unique challenges and opportunities in regard to the affordances of social media. This literature review highlights the state of our knowledge regarding this specific subset of patients using social media to support management of genetic diseases.

Health Information Technology is a major innovation at technological, social, and cultural levels [13]. Based on different studies, the implementation and adaptation of health information technologies is not an easy task, due to interrelated organizational, social, technological, personal, and environmental factors [14], [15], [16], [17]. Although health IT applications are used in hospitals, physician offices, and by patients at different levels, administrators and end users know little about the organizational changes, costs, work processes, communication patterns, and time required for successfully implementing systems [18]. Some scholars propose that $5 \%$ of health IT failures are related to technical factors [19], while others estimated that number to be as high as $20 \%$ [20]. According to [21], the problems that are reported are not related to the technology itself but to the lack of socio-technical considerations. Of course, technical problems such as lack of support, not having a user- 
friendly interface, and not having customized applications may cause failure in health information technology implementation; however, the main problems are often not technical, but rather sociotechnical. In the implementation and adaptation of health information technologies, there has been insufficient attention to socio-technical factors and healthcare providers have not been addressing these factors properly to make improvement in the hospitals [22], [23]. Instead of implementing technology and expecting people to adopt them, some have proposed better options would be modeling the system based on the capacity via a socio-technical approach and then predicting the impact of new technologies within the existing social systems [23].

O'Brien [24] explained that the United States is in the early stages of comprehending the advantages of digitizing healthcare. Health IT applications such as EHR were implemented with the purpose of ubiquitous access to patient records and an increase in the quality of care through the integration of patient data. However, the design of these systems has increased the documentation burden and decreased the ability to manage new work processes. Based on this study, "The phenomenon of 'data rich, information poor' in today's EHRs is all too often the reality for nursing" [25, p. 333]. A description of the focus of this literature review is presented in Figure 1.

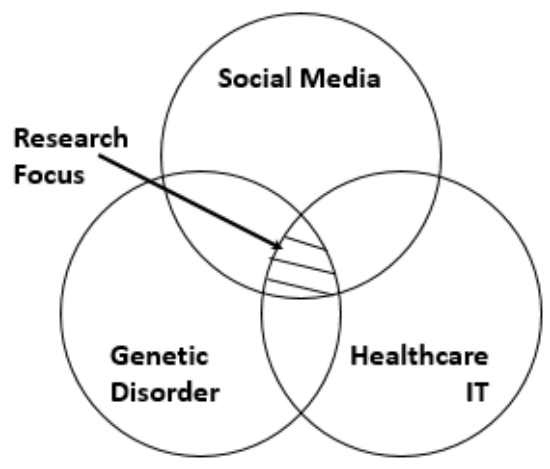

Figure 1 Research Focus

\section{Literature Review}

\subsection{Step 1: General Database Search}

We approach this review using standard methods of literature identification based on Cochrane Review types [26]. This study is categorized under qualitative reviews that synthesize qualitative and quantitative evidence to address questions on aspects other than effectiveness.

Our research considers three different types of technologies that support healthcare community development: online tools, social media and online communities. For the purposes of this research online tools are contextualized as technologies that support the publishing and distribution of content to an audience [27]. Examples of online tools include blogs or mobile applications that are used to publish health related content to interested parties. Social media is contextualized as technologies that support peer-topeer creation and sharing of content [28]. Examples of social media platforms include applications such as Facebook or Twitter. Online communities are contextualized as peer-to-peer communities that form within the social media platforms that are facilitate sharing among participants. These communities are possible through the peer-to-peer sharing capabilities that are afforded by social media platforms [29]. Online communities include Facebook pages dedicated to a particular topic. A summary of the constructs considered in our literature review are summarized in Table 1.

\begin{tabular}{|l|l|l|}
\hline Online tools & $\begin{array}{l}\text { Refers to technologies that } \\
\text { enable publishing and } \\
\text { distribution of content } \\
\text { online to an audience (like } \\
\text { a blog or an app) }\end{array}$ & [27] \\
\hline Social Media & $\begin{array}{l}\text { Refers to online platforms } \\
\text { that facilitate peer to peer } \\
\text { sharing of content amongst } \\
\text { participants }\end{array}$ & [28] \\
\hline $\begin{array}{l}\text { Online } \\
\text { Community }\end{array}$ & $\begin{array}{l}\text { Refers to online platforms } \\
\text { that facilitate peer to peer } \\
\text { sharing of content amongst } \\
\text { participants }\end{array}$ & [29] \\
\hline
\end{tabular}

Table 1: Summary of Constructs

The goal of systematic review is to deliver a complete and in-depth summary of current literature relevant to a research question. In the first step of conducting systematic review, the research question was created. In this case our research questions are focused on first, the evidence base of research that addresses the efficacy of social networking tools for use in pain mitigation among people with genetic disorders and second what social networking tools are used most frequently and effectively by patients with genetic-disorder conditions.

In the second step, a thorough search of the literature for relevant papers has been completed. Databases such as Pubmed, medline and other related medical databases have been investigated. The titles and abstracts of identified articles were checked based on the pre-determined criteria for eligibility and relevance to form the specified set. 
Our focus for choosing databased was based how much they are covering medical related research. Multiple database were searched in this study including Medline, Cochrane, Google Scholar, CINAHL, PsycINFO, and Proquest. The search terms used include online social media pain management, Facebook pain, Twitter pain, and Information Systems pain. More search terms were evaluated for inclusion, however, the results was either very broad or not related to our research questions and goals. These search keys were used for all fields such as title, abstract, keywords and full text). The results are shown in Table 2. The first column presents the names of different databases that were used in this study. The second column presents the number of total results based on the search key term and the last column presents the number of selected papers based on the study criteria.

\begin{tabular}{|l|l|l|}
\hline Library & $\begin{array}{l}\text { Total } \\
\text { number of } \\
\text { results }\end{array}$ & $\begin{array}{l}\text { Total number } \\
\text { of selected } \\
\text { papers }\end{array}$ \\
\hline Medline (Pubmed) & 634 & 48 \\
\hline Cochrane & 89 & 2 \\
\hline CINAHL & 19 & 8 \\
\hline PsycINFO & 8 & 2 \\
\hline
\end{tabular}

Table 2 Search Results

\subsection{Step 2: Focused Searches}

At the initial phase, different databases were selected, but after more detailed search, it was found that the results of some of these databases such as Google Scholar and ProQuest were overly broad for the scope of this study. Thus, these two databases were excluded from the final result. Given the context of the research the Medline (pubmed) database provides the most relevant and frequent collection of healthcare informatics peer-reviewed journals. Other databases such as Cochrance, CINHAL, and PsycINFO were searched, but most of their results were not identical and found in the Medline database.

The search results were refined based on the following criterion:

1) Peer-reviewed journal article

2) Different type of media; social networks such as Facebook and Twitter, and discussion board/forum such as Consumer Led Forum or Healthcare Organization Led Forum.

3) Role of Information systems and online communities as a pain management facilitator

4) Pain type mainly based on the body organ

5) Research methods (qualitative, quantitative, mixed)

6) Published date
Table 3 indicated the number of articles that meet the criteria and included in this study. The results were shown based on the search key term.

\begin{tabular}{|l|l|}
\hline Search Key Term & $\begin{array}{l}\text { Total number of } \\
\text { results }\end{array}$ \\
\hline $\begin{array}{l}\text { Online Social Media Pain } \\
\text { Management }\end{array}$ & 22 \\
\hline Social Media Pain & 12 \\
\hline Facebook Pain & 7 \\
\hline Twitter Pain & 7 \\
\hline
\end{tabular}

\section{Table 3 Results by Search Term}

\subsection{Step 3: Analysis}

The papers were analyzed and categorized based on the selected criteria (discussed in step 2). In order to group them, the title, abstract, and key words that were mentioned in the papers, were reviewed. The focus of our selection is patient-centered. Therefore papers that indicated their study subject was healthcare providers, staff, or physician that were excluded from our analysis. Our focus was on those papers that were researching the use of social media/online community tools by healthcare providers to assess patient's pain and record their pain.

After the detailed review, out of 56 papers, 48 were met the criteria and corresponded to the research questions.

\section{Results}

All together 48 papers were studied in the literature review. After the detailed review of selected papers, we conclude that common themes focused on how online/web-based tools can reduce the pain for patients. Papers often described different types of diseases or in summary how online/web-based tools can help the pain management. The pain management varied between different types of online tools that were used (section 4.1) and also different body organs and disease that were involved (section 4.2). Moreover, there are different effects of online community/webbased tools on pain that could have either positive or negative outcome (section 4.3). Furthermore, the results were categorized based on their qualitative or quantitative types and different methodologies (section 4.4) and their published date (section 4.5).

\subsection{Types of Information Technology tools (Social networks)}

After full reviews of selected papers, 9 different categories of social media and information technology tools were determined. Table 4 indicates the list of online tools that were examined in this study. Based on the statistics, most of the papers studied the role of mobile and web-based application in the pain 
reduction, discussion or pain-related communications. Twitter and online communities/ support group are the second and third most studied technology tools, respectively in the selected papers.

\begin{tabular}{|l|l|}
\hline Type of Media & Paper \\
\hline Blog and Discussion Forum & {$[30][31][32][33]$} \\
\hline Decision Support System & {$[34]$} \\
\hline Facebook & {$[35][36][37][38]$} \\
\hline Flickr and Tumblr & {$[39][40]$} \\
\hline YouTube & {$[41][42][43][44]$} \\
\hline $\begin{array}{l}\text { Online Communities/Support } \\
\text { Group }\end{array}$ & {$[45][46][47][48][49]$} \\
\hline Online Reviews/Comments & {$[50][51]$} \\
\hline Mobile/Web Pain & {$[52][53][54][55][56]$} \\
Management Apps & {$[57][58][59][60][61]$} \\
& {$[62][63][64][65][66]$} \\
& {$[67][68][69][70]$} \\
\hline Twitter & {$[71][72][73][74][75]$} \\
& {$[76][77]$} \\
\hline
\end{tabular}

Table 4 Technology Tool Summary

\subsection{Pain Types and Body Organ}

There are different types of physical pains that involving different body organ and based on different types of disease they are diverse. Chronic pain is the most discussed pain in our literature reviews. Chronic pain is defined as a pain that is ongoing and usually lasts longer than six months (Cleveland Clinic).

Based on [78], the occurrence of chronic pain in North America ranges from 19\% to 31\%. Different types of diseases such as Headache, Arthritis, Cancer, Nerve pain, Back pain, Fibromyalgia pain can cause the chronic pain. In this review, the disease that is related to chronic pain was not considered although the physical location of the pain was assessed. General pain refers to studies that were not mentioned the type or physical location of pain and just said "pain". Overall, the number of papers that discussed the impact of online tools on chronic pain management is in the first rank. The number of papers that addressed arthritis, dental and pediatric pain are ranked among the highest respectively after the general pain. Table 65indicates the types of pain in the reviewed papers.

\begin{tabular}{|l|l|}
\hline Pain Type & Paper \\
\hline Arthritis or Fibromyalgia & {$[54][36][49][63][69]$} \\
\hline Back Pain & {$[56][60][75]$} \\
\hline Cancer Pain & {$[57]$} \\
\hline Chronic Pain & {$[53][46][39][34][37]$} \\
& {$[48][30][59][61][62]$} \\
& {$[40][64][65][32][67]$} \\
& {$[70]$} \\
\hline Dental Pain & {$[71][74][76][77]$} \\
\hline General Pain & {$[55][35][45][47][73]$} \\
\hline
\end{tabular}

\begin{tabular}{|l|l|}
\hline & {$[66][51][68]$} \\
\hline Headache/Migraine & {$[72]$} \\
\hline Joint and Muscle Pain & {$[50][42]$} \\
\hline Pediatric Pain & {$[31][41][43][44]$} \\
\hline Postoperative Pain & {$[58][38]$} \\
\hline Psychological Pain & {$[52]$} \\
\hline
\end{tabular}

Table 5 Pain Type

\subsection{Reported Result}

According to a majority of the reviewed studies, using social media/online tools does have positive effects on the pain management. Table 6 summarizes the reported findings of the selected articles. Most of the reviewed papers reported positive results for applying online tools on managing their pain.

Many of the reviewed papers reported the positive role of social media and pain management application on patient communications. Patients are sharing their experiences with pain and communicate with their providers and peers. Several papers discussed that these applications may have an emotional function but may not actually reducing the physical pain. For example, some patients are sharing their real-time pain experience on Twitter and found it helpful. Also, some patients are looking for emotional support from their peers and support communities through humor. Another positive outcome of this literature review are the data that were gathered for making pain communications in a more effective format and form.

There were several papers that addressed other advantages of using technology tools on pain management. Based on these papers considered in this review, the positive outcome of online communities and social media tools is to increase patient's knowledge about the pain and giving more information about their diseases. Researchers have found that patients have a willingness to use social media to write about their pain, express their feeling and use it as a diary. Also, patients can learn how to manage their pain. Researchers are demonstrating that patients are learning about non-medical techniques for pain management. In this way better pain management communication may reduce dependency on pharmaceutical based pain management techniques exemplified by opioids. Social media may provide a conduit for providing chronic pain sufferers with resources to support self-care education.

There were few studies that focused on the technical aspects of designing pain management applications and online support groups for pain management. On these papers, the format and design of the pain management websites were discussed more frequently. Researchers have found that it is important to design a website that enables patients to easily share their information. By doing so website users have been 
found to more willing to use the site information for managing their pain.

In contrast some applications have been found to be ineffective. Based on some other studies, the outcome of mobile/web applications on pain management is not very positive if they are poorly designed. These apps are made by software engineers and without the physician input. Poorly designed applications have been found to be not very informative or based on accurate knowledge. This lack of medical information could cause some barriers to effective use. A citation summary of this analysis is presented in the table 6 .

\begin{tabular}{|l|l|}
\hline Results & Paper \\
\hline Positive/Reduced Pain & $\begin{array}{l}{[53][54][35][50][47][64]} \\
{[63]}\end{array}$ \\
\hline $\begin{array}{l}\text { Positive with some } \\
\text { concerns/Privacy } \\
\text { issue/Better format }\end{array}$ & {$[36][56][66][43]$} \\
\hline $\begin{array}{l}\text { Positive/Pain } \\
\text { Education/Informative }\end{array}$ & {$\left[\begin{array}{l}{[45][58][49][61][65][51]} \\
{[41][42][44]}\end{array}\right.$} \\
\hline $\begin{array}{l}\text { Positive/Better } \\
\text { Communication/Share } \\
\text { experience }\end{array}$ & {$[39][57][37][48][59][49]$} \\
\hline $\begin{array}{l}\text { Positive/Technical }[38][40][74][76][77] \\
\text { features }\end{array}$ & {$[32]$} \\
\hline $\begin{array}{l}\text { Could help/More studies } \\
\text { have needed }\end{array}$ & {$[46][60][70]$} \\
\hline Not very Positive & {$[55][72][62][73][30][31]$} \\
\hline
\end{tabular}

\section{Table 6 Reported Results}

\subsection{Types of Studies}

Table 8 shows the types of studies based on their methodology that were used in the research. As reported in Table 7 , most the studies were qualitative or mixed method. Fully quantitative studies were in the minority. The review indicated that research on the impact of social media/online community tools on pain management has more focused on using interviews with patients, sentiment/content analysis of their text communications, focused group, and observational study.

\begin{tabular}{|l|l|}
\hline Method & Paper \\
\hline Qualitative & {$[36][39][57][37][60]$} \\
& {$[62][40][30][31][76]$} \\
& {$[65][66][32][43][67]$} \\
& {$[68][33][69][44]$} \\
\hline Quantitative & {$[52][53][54][50][56]$} \\
& {$[47][49][71][72][38]$} \\
& {$[61][62]$} \\
\hline Mixed methods & {$[55][35][45][46][58]$} \\
& {$[48][30][59][63][73]$} \\
& {$[74][74][77][51][41]$} \\
& {$[42]$} \\
\hline
\end{tabular}

\section{Table 7 Methodology Summary}

\subsection{Published Date}

The published date of reviewed studies is another interesting point that should be considered. Most of the papers in the field of social media and technology tools effects on pain management are recent (41 papers after 2011). Although, it has been several years that patients have had access to social media and mobile/web applications, research regarding the effects of these technologies has lagged behind their adoption. The data shows that the application of social media in healthcare and pain management is still new and that additional critical areas of research likely remain unaddressed. A breakdown of total publication counts is presented in table 8 .

\begin{tabular}{|l|l|}
\hline Year & Number of papers \\
\hline 2019 & 3 \\
\hline 2018 & 5 \\
\hline 2017 & 5 \\
\hline 2016 & 10 \\
\hline 2015 & 6 \\
\hline 2014 & 7 \\
\hline 2013 & 1 \\
\hline 2012 & 1 \\
\hline 2011 & 3 \\
\hline
\end{tabular}

Table 8 Papers Published by Year

\section{Discussion}

Pain management is a growing concern in many societies. In the United States the cost of pain management -usually in the form of opioid drugs- is around $\$ 600$ billion per year [79]. To reduce the cost and decrease the risk of using opioid is critical to find a better way for pain reduction.

The popular usage of social media, online communities, and mobile/web applications could afford great opportunities to patients and healthcare providers to apply pain management techniques via these technologies.

Patients with Genetic disorders may be able to live as long as other people, but their life is accompanied with greater levels of pain. By reviewing the related literature, we have demonstrated that information technology tools could have an advantage in managing pain. However, despite the breadth of finding related to pain management that were revealed in our review, no papers were identified that address pain management for genetic disorders via social media or online applications. 


\subsection{Principal Findings}

Our finding highlight the growing importance of social media based research in examining topics regarding pain management. Major social media platforms have been in existence for over a decade. Facebook launched in 2004, Youtube in 2005 and Twitter in 2006. However, assessing the impact of these platforms within the context of health IT did not occur until after the platforms reached broad audiences. The first paper in our analysis examining the role of social media platforms on health management was not published until 2011, seven years after Facebook's launch. However since researchers began to examine the role of social media, 41 papers have been published highlighting the platforms' role in health management.

The relative novelty of using social media to analyze health management presents both challenges and opportunities to scholars. Challenges, as assessing technology use among disparate communities has been found to be difficult because the way that technology affords activities can vary within the healthcare environment [12]. Opportunities, as the still emerging affordances of social media are yet to be understood. The rapid increase in the number of papers published that examine social media highlights the extent to which our knowledge of the role of social media in enabling healthcare related communities is expanding. While the growth of knowledge regarding social media and healthcare communities has been valuable, our review highlights that our knowledge regarding chronic pain or genetic diseases is still relatively underdeveloped.

Our results highlight that while mobile applications have been relatively well represented in the literature, comparatively few studies have been completed regarding social media. The peer-to-peer structure of social media has been found to build communities of distributed individuals [3]. For rare diseases, which have a relatively small number of patients, the ways in which social media affords distributed groups to develop may be especially impactful. Furthering our understanding of how mobile devices can assist in pain management may provide a fertile source for future research contributions on the ways in which technology may afford patients alternatives to pharmaceutical pain management.

\subsection{Limitations of the Literature Review}

The healthcare literature spans many domains, which creates challenges in completing a literature review. Our review of necessity used a limited number of search terms, in targeted databases. Our focus was on the overlap of healthcare information technology, social media and rare genetic diseases, however a broader search in corollary literature to healthcare, such as psychology or genetics could reveal additional research which could provide insight regarding the use of social media in developing communities around rare diseases. The expansive nature of healthcare related literature presents both challenges and opportunities to conduct future research examining how technology affords health management behaviors in circumstances that extend beyond pain management.

\subsection{Avenues of Future Research}

The expanding research stream examining social media within healthcare management suggests that our knowledge in this domain is still developing. For specialized healthcare communities, such as rare genetic diseases, the potential benefits available through social media may be especially impactful. We propose that future research assessing the ways in which the affordances of social media enable communities dedicated to rare genetic diseases to develop would be of value to both scholars and practitioners.

Rare genetic diseases have the potential to create highly engaged communities of individuals, however without the peer-to-peer sharing capabilities afforded through social media communities dedicated to the management or rare genetic diseases have often struggled to reach a critical mass of participants. The distributed nature of social media enables communities to reach a critical mass of participants without the constraint of geographic boundaries. For scholars, the ability to study how technology affordances of social media provide unique value that would be unattainable without social media platforms may provide a unique perspective through which to articulate the value of information systems.

For practitioners who are struggling with rare genetic diseases future research could be especially impactful in enhancing patient quality of life. Hundreds of rare genetic diseases exist, and furthering our understanding of the characteristics of successful social media communities could be of benefit for individuals interested in encouraging the development of additional online communities for diseases with which they struggle.

\section{Conclusions}

The opioid crisis in the US highlights the important individual and societal challenges associated with pain management. Our findings demonstrate that while the literature regarding social media in healthcare management is growing, there are still opportunities to 
expand our knowledge regarding how social media can promote improved pain management of genetic diseases. Expanding our knowledge regarding how technology can better support these vulnerable

[1] Nithithanatchinnapat, B., Taylor, J., Joshi, K.D., and Weiss, M.L., "Organizational Communities of Practice: Review, Analysis, and Role of Information and Communications Technologies", Journal of Organizational Computing and Electronic Commerce, 26(4), 2016, pp. 307-322.

[2] Leong, C.M.L., Pan, S.L., Ractham, P., and Kaewkitipong, L., "Ict-Enabled Community Empowerment in Crisis Response: Social Media in Thailand Flooding 2011", Journal of the Association for Information Systems, 16(3), 2015, pp. 1.

[3] Patel, R., Chang, T., Greysen, S.R., and Chopra, V., "Social Media Use in Chronic Disease: A Systematic Review and Novel Taxonomy", The American journal of medicine, 128(12), 2015, pp. 1335-1350.

[4] Rare Disease Report. Available at: http://www.raredr.com/news/hospital-cf-cost

[5] Genetic and Rare Diseases Information Center (GARD). Available at: https://rarediseases.info.nih.gov/diseases/pages/31/faqsabout-rare-diseases

[6] National Human Genome Research Institute (NIH). Available at: https://www.genome.gov/19016930/faqabout-genetic-disorders/

[7] Muscular Dystrophy News Today. Available at: https://musculardystrophynews.com/2017/06/05/cost-

illness-neuromuscular-diseases-united-states/

[8] Miller, A.R., and Tucker, C., "Active Social Media Management: The Case of Health Care", Information systems research, 24(1), 2013, pp. 52-70.

[9] Korda, H., and Itani, Z., "Harnessing Social Media for Health Promotion and Behavior Change", Health promotion practice, 14(1), 2013, pp. 15-23.

[10] Yan, L., and Tan, Y., "Feeling Blue? Go Online: An Empirical Study of Social Support among Patients", Information systems research, 25(4), 2014, pp. 690-709.

[11] Mettler, T., "Contextualizing a Professional Social Network for Health Care: Experiences from an Action Design Research Study", Information Systems Journal, 28(4), 2018, pp. 684-707.

[12] Kallinikos, J., and Tempini, N., "Patient Data as Medical Facts: Social Media Practices as a Foundation for Medical Knowledge Creation", Information systems research, 25(4), 2014, pp. 817-833.

[13] Gagnon MP, Godin G, Gagné C, Fortin JP, Lamothe L, Reinharz D, Cloutier A. "An adaptation of the theory of interpersonal behaviour to the study of telemedicine adoption by physicians". International journal of medical informatics. 2003 Sep 1;71(2-3):103-15.

[14] Cresswell K, Sheikh A. "Organizational issues in the implementation and adoption of health information technology innovations: an interpretative review". International journal of medical informatics. 2013 May 1;82(5):e73-86. communities represents an important potential future contribution to the literatures.

\section{References}

[15] Vest JR. "More than just a question of technology: Factors related to hospitals' adoption and implementation of health information exchange”. International journal of medical informatics. 2010 Dec 1;79(12):797-806.

[16] Rippen HE, Pan EC, Russell C, Byrne CM, Swift EK. "Organizational framework for health information technology”. International journal of medical informatics. 2013 Apr 1;82(4):e1-3.

[17] Anderson JG. "Social, ethical and legal barriers to ehealth". International journal of medical informatics. 2007 May 1;76(5-6):480-3.

[18] Lluch M. "Healthcare professionals' organisational barriers to health information technologies-A literature review”. International journal of medical informatics. 2011 Dec 1;80(12):849-62.

[19] Middleton B. "Achieving US health information technology adoption: the need for a third hand". Health Affairs. 2005 Sep;24(5):1269-72.

[20] Westbrook JI, Braithwaite J, Iedema R, Coiera EW. "Evaluating the impact of information communication technologies on complex organizational systems: a multidisciplinary, multi-method framework”. InMedinfo 2004 Sep (pp. 1323-1327).

[21] Yee KC, Miils E, Airey C. "Perfect match? Generation $\mathrm{Y}$ as change agents for information communication technology implementation in healthcare". Studies in health technology and informatics. 2008;136:496.

[22] Wears RL, Berg M. "Computer technology and clinical work: still waiting for Godot”. Jama. 2005 Mar 9;293(10):1261-3.

[23] Coiera E. "Four rules for the reinvention of health care”. Bmj. 2004 May 13;328(7449):1197-9.

[24] O'brien A, Weaver C, Hook ML, Ivory CH. "EHR documentation: the hype and the hope for improving nursing satisfaction and quality outcomes". Nursing administration quarterly. 2015 Oct 1;39(4):333-9.

[25] Charles D, Gabriel M, Furukawa MF. "Adoption of electronic health record systems among US non-federal acute care hospitals: 2008-2013”. ONC data brief. 2014 May;16:1-9.

[26] Silva V, Grande AJ, Martimbianco AL, Riera R, Carvalho AP. "Overview of systematic reviews-a new type of study: part I: why and for whom?”. Sao Paulo Medical Journal. 2012;130(6):398-404.

[27] Greener, S., "Talking Online: Reflecting on Online Communication Tools", Campus-Wide Information Systems, 26(3), 2009, pp. 178-190.

[28] Yang, S.J., and Chen, I.Y., "A Social Network-Based System for Supporting Interactive Collaboration in Knowledge Sharing over Peer-to-Peer Network", International Journal of Human-Computer Studies, 66(1), 2008, pp. 36-50.

[29] Sarasohn-Kahn, J., "The Wisdom of Patients: Health Care Meets Online Social Media", in (Editor, 'ed.'^'eds.'): Book The Wisdom of Patients: Health Care Meets Online 
Social Media, California HealthCare Foundation Oakland, CA, 2008

[30] Rod K. "Finding ways to lift barriers to care for chronic pain patients: Outcomes of using internet-based self-management activities to reduce pain and improve quality of life”. Pain Research and Management. 2016.

[31] Curran-Smith J, Abidi SS, Forgeron P. "Towards a collaborative learning environment for children's pain management: leveraging an online discussion forum”. Health Informatics Journal. 2005 Mar;11(1):19-31.

[32] Tsai S, Crawford E, Strong J. "Seeking virtual social support through blogging: A content analysis of published blog posts written by people with chronic pain”. Digital health. 2018 May;4:2055207618772669

[33] Rodham K, Gavin J, Coulson N, Watts L. "Cocreation of information leaflets to meet the support needs of people living with complex regional pain syndrome (CRPS) through innovative use of wiki technology". Informatics for Health and Social Care. 2016 Jul 2;41(3):325-39.

[34] Trafton J, Martins S, Michel M, Lewis E, Wang D, Combs A, Scates N, Tu S, Goldstein MK. "Evaluation of the acceptability and usability of a decision support system to encourage safe and effective use of opioid therapy for chronic, noncancer pain by primary care providers”. Pain Medicine. 2010 Mar 31;11(4):575-85.

[35] Ho LC, Wu WH, Chiou WB. "Analgesic effect of Facebook: Priming with online social networking may boost felt relatedness that buffers against physical pain". Scandinavian journal of psychology. 2016 Oct;57(5):433-6. [36] des Bordes JK, Gonzalez E, Lopez-Olivo MA, Shethia M, Nayak P, Suarez-Almazor ME. “Assessing information needs and use of online resources for disease selfmanagement in patients with rheumatoid arthritis: a qualitative study”. Clinical rheumatology. 2018 Jul 1;37(7):1791-7.

[38] Rolbiecki AJ, Teti M, Crenshaw B, LeMaster JW, Ordway J, Mehr DR. "Exploring Lived Experiences of Chronic Pain Through Photo-Elicitation and Social Networking”. Pain Medicine. 2018 Sep 18.

[39] Dhar VK, Kim Y, Graff JT, Jung AD, Garrett J, Dick LE, Harris J, Shah SA. "Benefit of social media on patient engagement and satisfaction: Results of a 9-month, qualitative pilot study using Facebook”. Surgery. 2018 Mar 1;163(3):565-70

[40] Gonzalez-Polledo E, Tarr J. "The thing about pain: The remaking of illness narratives in chronic pain expressions on social media”. new media \& society. 2016 Sep;18(8):1455-72.

[41] Harrison D, Reszel J, Dagg B, Aubertin C, Bueno M, Dunn S, Fuller A, Harrold J, Larocque C, Nicholls S, Sampson M. "Pain Management During Newborn Screening”. The Journal of perinatal \& neonatal nursing. 2017 Apr 1;31(2):172-7.

[42] Meldrum S, Savarimuthu BT, Licorish S, Tahir A, Bosu M, Jayakaran P. "Is knee pain information on YouTube videos perceived to be helpful? An analysis of user comments and implications for dissemination on social media”. Digital health. 2017 Mar;3:2055207617698908.

[43] Harrison D, Wilding J, Bowman A, Fuller A, Nicholls SG, Pound CM, Reszel J, Sampson M. "Using YouTube to disseminate effective vaccination pain treatment for babies”. PloS one. 2016 Oct 3;11(10):e0164123.

[44] Harrison D, Sampson M, Reszel J, Abdulla K, Barrowman N, Cumber J, Fuller A, Li C, Nicholls S, Pound CM. "Too many crying babies: a systematic review of pain management practices during immunizations on YouTube”. BMC pediatrics. 2014 Dec;14(1):134.

[45] Whitman CB, Reid MW, Arnold C, Patel H, Ursos L, Sa'adon R, Pourmorady J, Spiegel BM. "Balancing opioidinduced gastrointestinal side effects with pain management: Insights from the online community”. Journal of opioid management. 2015;11(5):383-91.

[46] Long AC, Palermo TM. "Brief report: Web-based management of adolescent chronic pain: development and usability testing of an online family cognitive behavioral therapy program”. Journal of pediatric psychology. 2008 Jul 31;34(5):511-6.

[47] Bender JL, Radhakrishnan A, Diorio C, Englesakis M, Jadad AR. "Can pain be managed through the Internet? A systematic review of randomized controlled trials". PAIN®. 2011 Aug 1;152(8):1740-50.

[48] Young SD, Koussa M, Lee SJ, Perez H, Gill N, Gelberg L, Heinzerling K. "Feasibility of a social media/online community support group intervention among chronic pain patients on opioid therapy". Journal of addictive diseases. 2019 Jan 3:1-6.

[49] Willis E. "Patients' self-efficacy within online health communities: facilitating chronic disease self-management behaviors through peer education". Health communication. 2016 Mar 3;31(3):299-307.

[50] Adams DZ, Gruss R, Abrahams AS. "Automated discovery of safety and efficacy concerns for joint \& muscle pain relief treatments from online reviews". International journal of medical informatics. $2017 \mathrm{Apr}$ 1;100:108-20.

[51] Graves RL, Goldshear J, Perrone J, Ungar L, Klinger E, Meisel ZF, Merchant RM. "Patient narratives in Yelp reviews offer insight into opioid experiences and the challenges of pain management”. Pain management. 2018 Feb 16;8(2):95-104.

[52] Portelli P, Eldred C. A quality review of smartphone applications for the management of pain. British journal of pain. 2016 Aug;10(3):135-40.

[53] Ruehlman LS, Karoly P, Enders C. “A randomized controlled evaluation of an online chronic pain self management program”. Pain. 2012 Feb 1;153(2):319-30.

[54] Trudeau KJ, Pujol LA, DasMahapatra P, Wall R, Black RA, Zacharoff K. "A randomized controlled trial of an online self-management program for adults with arthritis pain”. Journal of behavioral medicine. 2015 Jun 1;38(3):483-96.

[55] Kuziemsky CE, Weber-Jahnke JH, Lau F, Downing GM. "An interdisciplinary computer-based information tool for palliative severe pain management”. Journal of the American Medical Informatics Association. 2008 May 1;15(3):374-82.

[56] Butler L, Foster NE. "Back pain online: a crosssectional survey of the quality of web-based information on low back pain”. Spine. 2003 Feb 15;28(4):395-401.

[57] Stinson JN, Jibb LA, Nguyen C, Nathan PC, Maloney AM, Dupuis LL, Gerstle JT, Alman B, Hopyan S, 
Strahlendorf C, Portwine C. "Development and testing of a multidimensional iPhone pain assessment application for adolescents with cancer”. Journal of medical Internet research. 2013;15(3):e51.

[58] Ingadottir B, Blondal K, Thue D, Zoega S, Thylen I, Jaarsma T. "Development, usability, and efficacy of a serious game to help patients learn about pain management after surgery: an evaluation study”. JMIR serious games. 2017;5(2):e10.

[59] Perry J, VanDenKerkhof EG, Wilson R, Tripp DA. "Guided internet-based psycho-educational intervention using cognitive behavioral therapy and self-management for individuals with chronic pain: A feasibility study". Pain Management Nursing. 2017 Jun 1;18(3):179-89.

[60] Nielsen M, Jull G, Hodges PW. "Information needs of people with low back pain for an online resource: a qualitative study of consumer views”. Disability and Rehabilitation. 2014 Jun 1;36(13):1085-91.

[61] Berman RL, Iris MA, Bode R, Drengenberg C. "The effectiveness of an online mind-body intervention for older adults with chronic pain”. The journal of Pain. 2009 Jan 1;10(1):68-79.

[62] Eckard C, Asbury C, Bolduc B, Camerlengo C, Gotthardt J, Healy L, Waialae L, Zeigler C, Childers J, Horzempa J. "The integration of technology into treatment programs to aid in the reduction of chronic pain”. Journal of pain management \& medicine. 2016;2(3).

[63] Lorig KR, Ritter PL, Laurent DD, Plant K. "The internet-based arthritis self-management program: A one-year randomized trial for patients with arthritis or fibromyalgia”. Arthritis Care \& Research: Official Journal of the American College of Rheumatology. $2008 \mathrm{Jul}$ 15;59(7):1009-17.

[64] Merolli M, Gray K, Martin-Sanchez F. “Therapeutic affordances of social media: emergent themes from a global online survey of people with chronic pain”. Journal of medical Internet research. 2014;16(12):e284.

[65] Williams DA. "Web-based behavioral interventions for the management of chronic pain". Current rheumatology reports. 2011 Dec 1;13(6):543.

[66] Henderson EM, Keogh E, Eccleston C. "Why go online when you have pain? A qualitative analysis of teenagers' use of the Internet for pain management advice”. Child: care, health and development. 2014 Jul;40(4):572-9.

[67] Merolli M, Gray K, Martin-Sanchez F. "Patient participation in chronic pain management through social media: A clinical study". InStudies in Health Technology and Informatics: Proceedings of the 13th International Congress in Nursing Informatics, 'Nursing Informatics 2016: eHealth for All: Every Level Collaboration-From Project to Realization', Geneva, Switzerland, 25-29 June 2016/Walter Sermeus, Paula M. Procter, Patrick Weber (eds.) 2016 (Vol. 225, p. 577).

[68] Merolli M, Gray K, Martin-Sanchez F, Mantopoulos S, Hogg M. "Using Social Media While Waiting in Pain: A Clinical 12-Week Longitudinal Pilot Study”. JMIR research protocols. 2015;4(3):e101.

[69] Merolli M, Gray K, Martin-Sanchez F, Lopez-Campos G. "Patient-reported outcomes and therapeutic affordances of social media: findings from a global online survey of people with chronic pain”. Journal of medical Internet research. 2015;17(1):e20.

[70] Merolli M, Gray K, Martin-Sanchez F, Schulz P. "Expert insights on the design and implementation of interactive patient websites for people with chronic pain”. InHIC 2014 Aug 14 (pp. 110-115).

[71] Heaivilin N, Gerbert B, Page JE, Gibbs JL. "Public health surveillance of dental pain via Twitter”. Journal of dental research. 2011 Sep;90(9):1047-51.

[72] Nascimento TD, DosSantos MF, Danciu T, DeBoer M, van Holsbeeck $H$, Lucas SR, Aiello C, Khatib L, Bender MA, Zubieta JK, DaSilva AF. "Real-time sharing and expression of migraine headache suffering on Twitter: a cross-sectional infodemiology study”. Journal of medical Internet research. 2014;16(4):e96.

[73] Tighe PJ, Goldsmith RC, Gravenstein M, Bernard HR, Fillingim RB. "The painful tweet: text, sentiment, and community structure analyses of tweets pertaining to pain”. Journal of medical Internet research. 2015;17(4):e84.

[74] Ahlwardt K, Heaivilin N, Gibbs J, Page J, Gerbert B, Tsoh JY. "Tweeting about pain: comparing self-reported toothache experiences with those of backaches, earaches and headaches". The Journal of the American Dental Association. 2014 Jul 1;145(7):737-43.

[75] Lee H, McAuley JH, Hübscher M, Allen HG, Kamper SJ, Moseley GL. "Tweeting back: predicting new cases of back pain with mass social media data”. Journal of the American Medical Informatics Association. 2015 Dec 11;23(3):644-8.

[76] Parsons CF, Breckons M, Durham J. "Twitter: a viable medium for daily pain diaries in chronic orofacial pain?”. British dental journal. 2015 Jul;219(2):75.

[77] Johnsen JA, Eggesvik TB, Rørvik TH, Hanssen MW, Wynn R, Kummervold PE. "Differences in Emotional and Pain-Related Language in Tweets About Dentists and Medical Doctors: Text Analysis of Twitter Content”. JMIR public health and surveillance. 2019;5(1):e10432.

[78] Chen E, Tsoy D, Upadhye S, Chan TM. "The Acute Care of Chronic Pain Study: Perceptions of Acute Care Providers on Chronic Pain, a Social Media-based Investigation”. Cureus. 2018 Mar;10(3).

[79] Eckard C, Asbury C, Bolduc B, Camerlengo C, Gotthardt J, Healy L, Waialae L, Zeigler C, Childers J, Horzempa J. "The integration of technology into treatment programs to aid in the reduction of chronic pain”. Journal of pain management \& medicine. 2016;2(3).

[80] Strong, D.M., Volkoff, O., Johnson, S.A., Pelletier, L.R., Tulu, B., Bar-On, I., Trudel, J., and Garber, L., "A Theory of Organization-Ehr Affordance Actualization", Journal of the Association for Information Systems, 15(2), 2014, pp. 2. 